Купреев С.C.

\title{
СОДЕРЖАНИЕ, ФОРМЫ И МЕТОДЫ АДМИНИСТРАТИВНОЙ ДЕЯТЕЛЬНОСТИ ПОЛИЦИИ
}

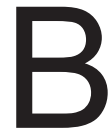

процессе своей деятельности органы полиции осуществляют значительное количество административных функций, при реализации которых они в соответствии со своей компетенцией вступают в особые правовые отношения с гражданами, государственными и общественными организациями и их должностными лицами. Административные функции полиции реализуются в рамках ее административной деятельности, которая наряду с уголовно-процессуальной, оперативно-розыскной деятельностью относится к числу наиболее важных и емких по содержанию видов работы.

Понятие административной деятельности известно отечественной праву еще с дореволюционных времен: до октября 1917 г. весьма распространенным было предложенное О. Майером определение административной деятельности как всякой государственной деятельности, не являющейся законодательной и судебной. Оперирование данным понятием продолжалось и в советское время. К примеру, И.И. Евтихиев понимал под административной деятельностью деятельность исполнительно-распорядительных органов в фрорме издания актов управления и применения мер принуждения. По его мнению, конкретное содержание административной деятельности должно определяться теми задачами, которые призвано разрешить государственное управление на определенном этапе развития государства'.

Указанные представления находят свое подтверждение и в современных подходах к определению административной деятельности, которая рассматривается

${ }^{1}$ См.: Евтихиев И.И. Виды и формы административной деятельности органов государственного управления. Дис. ... д-ра юрид. наук. М., 1948. С. 174, 188. как в общем, так и в прикладных аспектах. Наиболее общее определение административной деятельности в современной науке административного права предлагает Д.Н. Бахрах: «Административная деятельность - это систематическая, непрерывная организация, направленная на сохранение социальной системы, ее укрепление, развитие»². В прикладном аспекте, применительно к определенному органу исполнительной власти или совокупности органов с однородной компетенцией, вопросы административной деятельности чаще всего рассматриваются с позиций органов внутренних дел. В данном контексте административная деятельность органов внутренних дел определяется как «целенаправленная, организующая исполнительная и распорядительная деятельность, состоящая в непосредственном, повседневном, практическом осуществлении задач и функций государства в сфере внутренних дел» ${ }^{3}$. Существует и такое определение: «Административная деятельность органов внутренних дел представляет собой исполнительно-распорядительную деятельность по организации работы подчиненных аппаратов, служб, подразделений, их сотрудников и практическому осуществлению административно-правовыми способами, формами и методами охраны общественного порядка, обеспечения общественной безопасности и борьбы с преступностью» ${ }^{4}$.

\footnotetext{
${ }^{2}$ Бахрах Д.Н. Административное право России: учебник для вузов. М., 2000. С. 10.

3 Административная деятельность органов внутренних дел: часть общая: учебник. М., 1998. С. 38.

4 Административная деятельность органов внутренних дел: учебное пособие для вузов / под ред. проф. В.Я. Кикотя. М.: ЮНИТИ-ДАНА, Закон и право, 2003. С. 24.
} 


\section{Полицейская деятельность 2 • 2014}

Разработанные теорией административного права общие подходы к определению административной деятельности, а также приведенные определения данного понятия, позволяют выделить ряд признаков административной деятельности полиции.

Государственно-властный характер административной деятельности полиции выражается в том, что она осуществляется от имени государства с учетом тех актуальных задач в сфере внутренних дел, которые призваны решать государственные институты на конкретном этапе развития страны.

Исполнительно-распорядительный, подзаконный характер административной деятельности полиции означает, что она направлена на повседневное, непосредственное, практическое исполнение законодательных актов РФ, актов Президента РФ и Правительства РФ в сфере внутренних дел, то есть по вопросам охраны общественного порядка, обеспечения общественной безопасности и борьбы с преступностью. Для выполнения данных задач органы полиции наделяются широким кругом административно-распорядительных полномочий, в том числе по применению мер административного принуждения.

Предупредительная, профрилактическая направленность административной деятельности полиции проявляется в максимально упреждающем воздействии на общественные группы и отдельные личности в целях недопущения совершения противоправных действий, оперативного их пресечения.

Административная деятельность должна осуществляться четко в рамках установленной государством компетенции. Органы полиции при реализации своих административных функций не должны уклоняться от реализации своей компетенции, равно как и выходить за ее пределы. Устанавливая компетенцию государственного органа, государство ставит его в опреде- ленные рамки, за несоблюдение которых конкретные должностные лица несут юридическую ответственность.

Существуют «узкий» и «широкий» подходы к пониманию содержания административной деятельности органов исполнительной власти (в том числе органов полиции).

Согласно «узкому» подходу, основное содержание административной деятельности составляет внешняя правоприменительная деятельность по реализации административных полномочий. Но какие именно полномочия являются административными? Ответ на данный вопрос кроется в понятии правоприменительной деятельности органов исполнительной власти. Одно из наиболее удачных определений данного понятия дал в свое время В.А. Юсупов: это «оперативно-исполнительная или юрисдикционная государственно-властная, подзаконная деятельность исполнительно-распорядительных органов, направленная на осуществление конкретных функций государственного управления» 5 . Изложенное определение, рассматриваемое через призму современного административно-правового регулирования, позволяет обозначить два самостоятельных блока административных полномочий, реализуемых органами исполнительной власти (в том числе органами полиции): процедурные (реализация административных процедур) и юрисдикционные. Реализация этих двух блоков административных полномочий и составляет содержание административной деятельности полиции (в узком ее понимании).

По своему содержанию административно-процедурная деятельность охватывает реализацию органами полиции государственных функций в административно-правовой сфрере. Государственные фрункции, реализуемые органами внутрен-

\footnotetext{
${ }^{5}$ Юсупов В.А. Правоприменительная деятельность органов управления. М.: Юридическая литература, 1979. С. 24.
} 
них дел, вытекают из перечня основных функций органов исполнительной власти, закрепленного Указом Президента РФ от 9 марта 2004 года № 314 «О системе и структуре федеральных органов исполнительной власти». Так, в административноправовой сорере органы исполнительной власти реализуют:

- функции по контролю и надзору, в том числе осуществление действий по контролю и надзору за исполнением общеобязательных правил поведения; выдача разрешений (лицензий) на осуществление определенного вида деятельности и (или) конкретных действий юридическим лицам и гражданам; регистрация актов, документов, прав, объектов, а также издание индивидуальных правовых актов;

- функции по оказанию государственных услуг, то есть предоставление услуг гражданам и организациям в области образования, здравоохранения, социальной защиты населения и в других областях, установленных фредеральными законами.

В ходе проведенной в Российской Федерации административной реформы ${ }^{6}$ внедрена система стандартов реализации государственных функций и предоставления государственных услуг ${ }^{7}$. По каждой фрункции и услуге разрабатывается соответствующая административная процедура, закрепляемая в рамках административного регламента и включающая в себя ряд элементов: процедурные правила, предназначенные для легального применения материально-компетенционных норм; типичный «набор» юридических документов, принимаемых субъектами компетенции; стадии и виды деятельности субъектов компетенции и связанных с ними других

\footnotetext{
${ }^{6}$ См. Концепцию административной реформы в Российской Федерации в 2006-2010 годах, утвержденную распоряжением Правительства РФ от 25 октября 2005 года № 1789-p.

${ }^{7}$ См. Федеральный закон от 27 июля 2010 года № 210Ф3 «Об организации предоставления государственных и муниципальных услуг».
}

субъектов права, последовательность совершения юридических действий и их связь; временная характеристика (сроки, продолжительность, периодичность) $)^{8}$.

В рамках административно-процедурной деятельности органы полиции осуществляют лицензионно-разрешительные процедуры, регистрационное производство, в частности, в сферах обеспечения безопасности дорожного движения; контроля за соблюдением законодательства в области оборота оружия; контроля за соблюдением законодательства в области частной детективной (сыскной) и охранной деятельности. Все административные процедуры, осуществляемые органами полиции, реализуются в соответствии с указанными выше стандартами ${ }^{9}$.

Кроме того, в рамках административно-процедурной деятельности органы полиции осуществляют производство по жалобам. Производство по жалобам направлено на защиту прав и законных интересов лиц, подавших жалобу. Согласно ст. 33 Конституции Российской Федерации, граждане имеют право обращаться лично, а также направлять индивидуальные и коллективные обращения в государственные органы и органы местного самоуправления. Общий порядок рассмотрения жалоб граждан регламентируется Федеральным законом «О порядке рассмотрения обращений граждан Российской Федерации».

Административно-юрисдикционная деятельность органов исполнительной власти (в том числе органов полиции) представляет собой установленную нормами

\footnotetext{
${ }^{8}$ См.: Тихомиров Ю.А. Административные процедуры: доктрина и практика // Административные процедуры и контроль в свете европейского опыта / Под ред. Т.Я. Хабриевой и Ж. Марку. М.: Статут, 2011. С. 324.

${ }^{9}$ См., например, приказ МВД России от 7 ноября 2011 г. № 1121«Об утверждении Административного регламента Министерства внутренних дел Российской Федерации по предоставлению государственной услуги по выдаче справок о наличии (отсутствии) судимости и (или) факта уголовного преследования либо о прекращении уголовного преследования».
} 


\section{Полицейская деятельность 2 • 2014}

административного права совокупность полномочий органов исполнительной власти и их должностных лиц разрешать во внесудебном порядке споры в административно-правовой сфере и привлекать лиц к юридической ответственности. Специфическими чертами административной юрисдикции являются правоохранительный, принудительный характер, а также множественность субъектов, ее осуществляющих.

В рамках административно-юрисдикционной деятельности органы полиции осуществляют производство по делам об административных правонарушениях. Данный вид производства осуществляется в соответствии с требованиями Кодексом Российской Федерации об административных правонарушениях (КоАП РФ) и является административно-процессуальной деятельностью, реализуемой органами внутренних дел и их должностными лицами. Задачами производства по делам об административных правонарушениях являются всестороннее, полное, объективное и своевременное выяснение обстоятельств каждого дела, разрешение его в соответствии с законом, обеспечение исполнения вынесенного постановления, а также выявление причин и условий, способствовавших совершению административных правонарушений.

Производство по делам об административных правонарушениях включает в себя возбуждение дела об административном правонарушении, административное расследование, рассмотрение дела об административном правонарушении, сбор и оценку доказательств, применение мер обеспечения производства по делам об административных правонарушениях, принятие решения по делу, пересмотр постановлений и решений по делам об административных правонарушениях, исполнение постановлений.

При «широком» подходе к определению административной деятельности органов внутренних дел в ее содержании вы- деляется и так называемая внутриорганизационная деятельность. Она обеспечивает четкое функционирование служб и подразделений органов внутренних дел, в том числе распределение функциональных обязанностей, определение структуры штатов, планирование и контроль работы, подбор, расстановку и воспитание кадров, делопроизводство и т.д. Внутриорганизационная деятельность охватывает все службы и подразделения органов внутренних дел, включая и те, которые осуществляют оперативно-розыскную и уголовнопроцессуальную деятельность. Она складываются из руководства со стороны вышестоящих органов работой подчиненных органов и непосредственного управления начальниками и другими должностными лицами внутри каждого органа (службы).

В рамках внутриорганизационной деятельности в органах внутренних дел осуществляется дисциплинарное производство. Данный вид производства заключается в применении к государственным служащим, совершившим правонарушение в виде должностного проступка, дисциплинарных взысканий. Характерным для дисциплинарного производства является то, что дисциплинарное взыскание налагается в порядке служебного подчинения, то есть должностным лицом, которому государственный служащий подчинен по службе и обладающим в отношении государственного служащего дисциплинарной властью. Дисциплинарное производство в органах внутренних дел осуществляется в соответствии с Дисциплинарным уставом органов внутренних дел Российской Федерации, утвержденным Указом Президента РФ от 14 октября 2012 года № 1377.

Несмотря на всю важность и необходимость, внутриорганизационная деятельность имеет вспомогательное значение и призвана обеспечить надлежащую организацию работы органов полиции по выполнению возложенных на них задач, на- 
правленных вовне. Напротив, внешняя административная деятельность полиции является основной, так как в процессе еe осуществления практически реализуются задачи и функции, определяющие ее назначение. Она выходит за рамки внутриорганизационных отношений и распространяется на граждан, а также на неподчиненные государственные и негосударственные организации.

Таким образом, административная деятельность полиции представляет собой самостоятельный вид деятельности органов полиции, носящий властный исполнительно-распорядительный характер и заключающийся в реализации ими в пределах своей компетенции внешних административно-процедурных и административно-юрисдикционных полномочий, а также в осуществлении внутриорганизационной деятельности для обеспечения четкого фрункционирования подразделений органов полиции.

Административная деятельность полиции осуществляется в конкретных фоормах и определенными методами, которые закрепляются в законах и иных нормативных правовых актах и связаны с реализацией полицией своей компетенции. Под формой административной деятельности понимается определенное административноправовыми нормами внешне выраженное действие органа полиции или конкретного должностного лица, осуществляемое в рамках их компетенции и вызывающее определенные правовые последствия.

Административная деятельность полиции довольно многообразна, ее виды могут классифицироваться по содержанию и способу выражения.

По содержанию формы административной деятельности подразделяются на правотворческую и правоприменительную. Правотворческая деятельность состоит в выработке правовых норм, их совершенствовании (изменении, дополнении, отмене), то есть в издании нормативных пра- вовых актов, направленных, как правило, на регулирование внутриорганизационной деятельности органов внутренних дел. Она осуществляется на основе и во исполнение законодательных актов, актов Президента РФ, Правительства РФ, других органов государственной власти и носит подзаконный характер. Правоприменительная деятельность полиции состоит в принятии индивидуальных имеющих юридическое значение актов, т.е. в разрешении на основе норм права индивидуальных конкретных дел и совершении действий юридического характера. Любой орган внутренних дел (полиции) как субъект применения права в том или ином объеме обладает правоприменительной компетенцией, повседневно реализует фрункции управления в сорере внутренних дел.

По форме выражения фрормы административной деятельности могут подразделяться на письменные и устные. Письменная форма является основной, она используется при решении вопросов, требующих письменного оформления действий субъектов административной деятельности. Содержание данной формы административной деятельности заключается в подготовке и принятии органами полиции правовых актов (нормативных и индивидуальных), а также совершении юридически значимых действий (составление протоколов, регистрационных актов, выдача справок и др.). Устная форма административной деятельности применяется в предусмотренных нормативными правовыми актами случаях при решении вопросов оперативного характера и состоит в отдании устных приказов, распоряжений и команд, влекущих правовые последствия ${ }^{10}$.

Важнейшей фрормой административной деятельности является административ-

\footnotetext{
${ }^{10}$ См.: Административное право Российской Федерации: учебник для бакалавров / Ю.И. Мигачев, Л.Л. Попов, С.В. Тихомиров; под ред. Л.Л. Попова. 3-е изд., перераб. и доп. М.: Издательство Юрайт, 2013. С. 164.
} 


\section{Полицейская деятельность 2 • 2014}

ный акт. Данный термин наиболее зримо выражает волевое властное действие органа исполнительной власти, включающее волеизъявление органа (решение) и его внешнее выражение - акт в процессе выполнения функций, предоставления государственных услуг, порученных ему юридическими предписаниями, имеющий своей целью вызвать необходимые юридические последствия в соответствующих административно-правовых отношения $\mathrm{x}^{11}$. Издавая административный акт, орган исполнительной власти осуществляет свою компетенцию и реализует свои права не в силу своего желания, но в силу возложенной на него обязанности активно использовать свои права ${ }^{12}$.

Понятие административного акта охватывает как подготовку и принятие субъектами административной деятельности правовых актов (нормативных и индивидуальных), так и совершение юридически значимых действий. Характерными чертами административного акта являются: подзаконность, правовой характер, авторитарность, императивность. Подзаконный характер административного акта означает, что он издается в соответствии с законодательными актами, актами Президента РФ, Правительства РФ, актами федеральных органов исполнительной власти и в рамках компетенции органа, издающего административный акт. Правовой характер административного акта выражается в том, что он вызывает определенные юридические последствия. Административный акт обладает признаком авторитарности, так как представляет собой одностороннее волеизъявление субъекта административной деятельности. Наконец, императивность

\footnotetext{
11 См.: Ноздрачев А.Ф. Административные решения и акты в России и во Франции // Административные процедуры и контроль в свете европейского опыта / Под ред. Т.Я. Хабриевой и Ж. Марку. М.: Статут, 2011. С. 135.

${ }^{12}$ См.: Евтихиев И.И. Виды и формы административной деятельности органов государственного управления. Дис. ... д-ра юрид. наук. М., 1948. С. 393.
}

административного акта означает, что он обязателен для исполнения независимо от воли исполнителей.

К административным актам предъявляются конкретные требования. Так, в частности, административный акт издается в соответствии с законодательством, в пределах компетенции органа административной власти, в определенном порядке, по установленной форме и подписывается уполномоченным должностным лицом.

Еще одной формой административной деятельности является заключение административно-правовых договоров. Административно-правовой договор представляет собой основанный на административно-правовых нормах и выработанный в публичных интересах в результате добровольного согласования воли двух (либо более) субъектов административного права, одним из которых всегда выступает субъект административной власти, многосторонний акт, устанавливающий (прекращающий, изменяющий) взаимные права и обязанности его участников.

Одной из сторон административно-правового договора всегда выступает орган административной власти. Его основное содержание составляют управленческие отношения, заключается административно-правовой договор на основе добровольного согласия сторон. В литературе по административному праву основным критерием для классификации административно-правовых договоров является предмет договора: по данному критерию выделяются договоры о компетенции, договоры о сотрудничестве, договоры о поступлении на государственную службу.

Применительно к административной деятельности полиции самым распространенным видом административно-правового договора является контракт о прохождении службы в органах внутренних дел. Согласно ст. 21 Федерального закона от 30 ноября 2011 года № 342-Ф3 «О службе в органах внутренних дел Российской Фе- 
дерации и внесении изменений в отдельные законодательные акты Российской Федерации», данный контракт представляет собой соглашение между руководителем федерального органа исполнительной власти в сорере внутренних дел или уполномоченным руководителем и гражданином, поступающим на службу в органы внутренних дел, или сотрудником органов внутренних дел о прохождении службы в органах внутренних дел и (или) замещении должности в органах внутренних дел. Контрактом устанавливаются права и обязанности сторон. Законом устанавливаются виды и сроки действия контракта, а также требования к его содержанию.

Административная деятельность полиции осуществляется определенными методами, которые рассматриваются в единстве с фрормами административной деятельности: они являются взаимосвязанными и взаимообусловленными. В общепринятом понимании метод означает способ, прием практического осуществления чего-либо. Основой для применения методов административной деятельности полиции выступают два общих универсальных способа воздействия на сознание и волю людей в любой сфере деятельности: убеждение и принуждение. Убеждение является главным, определяющим методом воздействия. Оно связано с привлечением граждан, широкой общественности и средств массовой информации к решению государственно-управленческих задач, с воспитанием сознательной дисциплины, законопослушания и личной ответственности каждого. Убеждение выступает как средство профрилактики правонарушений и укрепления дисциплины. Мерами убеждения являются разъяснение, обоснование, обсуждение, внушение, поощрение, показ положительных примеров и многое другое. Общей правовой основой убеждения является сорормулированное в статье 15 Конституции РФ положение о том, что федеральные органы исполнительной власти, органы исполнительной власти субъектов РФ и органы местного самоуправления, должностные лица, граждане и их объединения обязаны соблюдать Конституцию РФ и фредеральные законы. Принуждение традиционно рассматривается в качестве вспомогательного метода воздействия, используемого в случаях, когда убеждение не дает результатов.

На базе указанных универсальных методов воздействия разрабатывается система методов административной деятельности, под которыми понимаются определенные административно-правовыми нормами конкретные приемы и способы деятельности органов внутренних дел и их должностных лиц, осуществляемые в рамках их компетенции и вызывающие определенные правовые последствия.

Методы административной деятельности полиции обладают следующими признаками:

они используются в процессе реализации административных полномочий органов полиции в сфрере охраны общественного порядка, обеспечения общественной безопасности и борьбы с преступностью;

они определены нормами права, закрепленными в законодательных и иных правовых актах, определяющих полномочия субъектов административной деятельности;

они выражаются в конкретных приемах и способах реализации субъектами административной деятельности задач в пределах своей компетенции ${ }^{13}$.

По своему содержанию методы административной деятельности полиции подразделяются на два блока.

Первый блок методов административной деятельности связан с осуществлением полицией процедурной деятельности.

\footnotetext{
${ }^{13}$ См.: Административное право Российской Федерации: учебник для бакалавров / Ю.И. Мигачев, Л.Л. Попов, С.В. Тихомиров; под ред. Л.Л. Попова. 3-е изд., перераб. и доп. М.: Издательство Юрайт, 2013. С. 177.
} 


\section{Полицейская деятельность 2 • 2014}

В данную группу методов входят лицензирование, регистрация, контроль и административный надзор.

Лицензирование является одним из ключевых методов административной деятельности полиции и связано с допуском предпринимателей к осуществлению различных видов деятельности. Лицензирование применяется только в тех случаях, когда невозможно в силу разных причин выделить определенные качества субъекта или объекта, в результате чего появляется риск нанесения ущерба при осуществлении деятельности широкому кругу третьих лиц.

Правовые основы осуществления лицензирования в Российской Федерации (понятие, цели, задачи, принципы и др.) установлены Федеральным законом «О лицензировании отдельных видов деятельности». Согласно данному Закону, под лицензированием понимается деятельность лицензирующих органов по предоставлению, переоформлению лицензий, продлению срока действия лицензий в случае, если ограничение срока действия лицензий предусмотрено федеральными законами, осуществлению лицензионного контроля, приостановлению, возобновлению, прекращению действия и аннулированию лицензий, фрормированию и ведению реестра лицензий, формированию государственного информационного ресурса, а также по предоставлению в установленном порядке информации по вопросам лицензирования. В то же время, данный Закон имеет ограниченную сферу регулирования: лицензирование ряда видов деятельности осуществляется в соответствии с отдельными законодательными актами.

Органы полиции осуществляют лицензирование частной охранной деятельности и частной детективной (сыскной) деятельности, а также в соответствии с Федеральным законом «Об оружии» выдают гражданам и организациям лицензии на приобретение оружия, лицензии на осуществление деятельности, связанной с оборотом оружия и боеприпасов.
Регистрация представляет собой деятельность специально уполномоченных органов исполнительной власти, состоящая в официальном признании юридических фрактов. Последствием регистрационных действий является приобретение различными субъектами дополнительных прав, например, права заниматься предпринимательской деятельностью для юридических лиц, в полной мере осуществлять гражданские права в отношении имущества. Примером регистрационных действий, осуществляемых полицией, может служить государственная регистрация автомототранспортных средств ${ }^{14}$.

В обобщенном виде процедуру регистрации можно представить в виде следующих этапов:

представление заинтересованным субъектом в орган, уполномоченный осуществлять регистрацию, установленных нормативными правовыми актами документов;

оценка соответствующими должностными лицами представленных документов, проверка указанных в них сведений;

регистрация определенного юридического фракта либо отказ в его осуществлении;

выдача документов, подтверждающих прохождение государственной регистрации, - свидетельств.

Контроль как метод административной деятельности состоит в том, что уполномоченные государственные органы и должностные лица, используя определенные приемы и способы, выясняют, насколько соответствует требованиям законодательства практическое осуществление подконтрольного вида деятельности. Как правило, подобный контроль проводится в рамках лицензионно-разрешительной системы, когда граждане и организации осуществляют какую-либо

\footnotetext{
${ }^{14}$ См. приказ МВД России от 7 августа 2013 года № 605 «Об утверждении Административного регламента Министерства внутренних дел Российской Федерации по предоставлению государственной услуги по регистрации автомототранспортных средств и прицепов к ним».
} 
деятельность в соответствии с предварительно полученным разрешением (лицензией). При выявлении каких-либо нарушений в процессе осуществления контроля контролирующие органы принимают меры по их устранению, восстановлению нарушенных прав, привлечению виновных лиц к ответственности. В соответствии с Федеральным законом "О полиции», полиция, в частности, контролирует оборот гражданского, служебного и наградного оружия, боеприпасов, патронов к оружию, сохранность и техническое состояние боевого ручного стрелкового и служебного оружия, находящегося во временном пользовании у граждан и организаций, а также соблюдение гражданами и организациями законодательства в области оборота оружия, деятельность частных детективов и частных охранных организаций, а также участвует в осуществлении контроля за соблюдением гражданами Российской Федерации и должностными лицами порядка регистрации и снятия граждан с регистрационного учета по месту пребывания и по месту жительства, а также за соблюдением иностранцами порядка въезда (выезда), пребывания (проживания) в Российской Федерации.

Административный надзор заключается в постоянном систематическом наблюдении уполномоченных государственных органов и их должностных лиц за соблюдением гражданами и организациями установленных правил поведения (деятельности). Характерными чертами административного надзора являются отсутствие отношений организационной подчиненности между органами надзора и поднадзорными объектами и наличие специального объекта надзорной деятельности. Примерами осуществления органами полиции административного надзора являются надзор за соблюдением участниками дорожного движения правил дорожного движения и надзор за гражданами, освобожденными из мест лишения свободы.
Второй блок методов административной деятельности полиции связан с осуществлением действий принудительного характера. Административно-правовое принуждение - это особый вид государственного принуждения, состоящий $в$ применении уполномоченными субъектами установленных нормами административного права принудительных мер в связи с совершением или угрозой совершения правонарушений. Методы административного принуждения исходя из целей использования, способов обеспечения правопорядка, общественной безопасности, специфрики возникающих при этом правоотношений подразделяются на четыре группы: меры административного предупреждения; меры административного пресечения; меры обеспечения производства по делам об административных правонарушениях; меры административного наказания.

Меры административного предупреждения применяются при возникновении обстоятельств, условий, при которых возможно совершение правонарушений. Подобные меры имеют ярко выраженную профрилактическую направленностью. Профилактическое воздействие играет ключевую роль в системе методов административной деятельности полиции. Применение предупредительных мер профилактики способствует воспитанию правосознания граждан, удерживая отдельных лиц от противоправных деяний и тем самым ограждая их самих и все общество от негативных последствий, наступающих вследствие совершения правонарушения. Как в свое время писал один из классиков юридической науки Чезаре Беккариа, «лучше предупреждать преступления, чем наказывать. В этом - главная цель всякого хорошего законодательства, которое является искусством вести людей к возможно большему счастью или к возможно меньшему несчастью, если говорить об общем итоге добра и зла в жизни» ${ }^{15}$.

${ }^{15}$ Беккариа Ч. О преступлениях и наказаниях. М.,2011. С. 150. 


\section{Полицейская деятельность 2 • 2014}

В рамках реализации мер административного предупреждения полиция в соответствии с Федеральным законом «О полиции» вправе:

- проверять документы, удостоверяющие личность граждан, проверять у граждан, должностных лиц, общественных объединений и организаций разрешения (лицензии) и иные документы на совершение определенных действий или на осуществление определенного вида деятельности, контроль (надзор) за которыми возложен на полицию;

- патрулировать населенные пункты и общественные места, оборудовать при необходимости контрольные и контрольнопропускные пункты, выставлять посты (в том числе стационарные) и заслоны, использовать другие формы охраны общественного порядка;

- требовать от граждан (групп граждан) покинуть место совершения преступления, административного правонарушения, место происшествия, не допускать граждан на отдельные участки местности и объекты, обязывать их оставаться на соответствующих участках местности и объектах или покинуть их; обращаться к группам граждан, нахождение которых в общественных местах не связано с проводимыми на законных основаниях публичными и массовыми мероприятиями, с требованием разойтись или перейти в другое место, если возникшее скопление граждан создает угрозу их жизни и здоровью, жизни и здоровью других граждан, объектам собственности, нарушает работу организаций, препятствует движению транспорта и пешеходов;

- вносить руководителям и должностным лицам организаций обязательные для исполнения представления об устранении причин и условий, способствующих реализации угроз безопасности граждан и общественной безопасности, совершению преступлений и административных правонарушений;
- осуществлять в целях обеспечения безопасности граждан и общественного порядка совместно с организаторами публичных и массовых мероприятий личный осмотр граждан, находящихся при них вещей при проходе на территории сооружений, на участки местности либо в общественные места, где проводятся такие мероприятия, с применением в случае необходимости технических средств, а при отказе гражданина подвергнуться личному осмотру не допускать его на такие территории, участки местности и в такие общественные места;

- осуществлять предполетный досмотр пассажиров воздушных судов, в том числе вещей, находящихся при пассажирах.

Меры административного пресечения уже направлены на принудительное прекращение противоправных действий граждан, должностных лиц, организаций, нарушающих установленные административно-правовыми нормами правила поведения. Они применяются в момент совершения правонарушения. Примерами применения органами полиции мер административного пресечения являются следующие права полиции:

- требовать от граждан и должностных лиц прекращения противоправных действий;

- проводить оцепление (блокирование) участков местности, жилых помещений, строений и других объектов;

- применять физическую силу, специальные средства и оружие;

- осуществлять задержание лиц в административном порядке;

- изымать оружие в случае грубого нарушения юридическими лицами и гражданами правил оборота оружия до принятия окончательного решения в порядке, установленном законодательством;

- аннулировать и изымать лицензии на приобретение оружия и (или) разрешения на хранение или хранение и ношение оружия

Меры обеспечения производства по делам об административных правонару- 
шениях и меры административного наказания регламентированы Кодексом Российской Федерации об административных правонарушениях (КоАП РФ). Они применяются в процессе административно-юрисдикционной деятельности полиции. Меры обеспечения производства по делам об административных правонарушениях осуществляются в целях пресечения административного правонарушения, установления личности нарушителя, составления протокола об административном правонарушении при невозможности его составления на месте выявления административного правонарушения, обеспечения своевре- менного и правильного рассмотрения дела об административном правонарушении и исполнения принятого по делу постановления. Исчерпывающий перечень обеспечительных мер установлен ст. 27.1 КоАП РФ. В свою очередь, административное наказание представляет собой установленную государством меру ответственности за совершение административного правонарушения. Административное наказание применяется в целях предупреждения совершения новых правонарушений как самим правонарушителем, так и другими лицами. Исчерпывающий перечень административных наказаний установлен ст. 3.2 КоАП РФ.

\section{Библиография:}

1. Административная деятельность органов внутренних дел: учебное пособие для вузов / под ред. проф. В.Я. Кикотя. М.: ЮНИТИ-ДАНА, Закон и право, 2003.

2. Административное право Российской Федерации: учебник для бакалавров / Ю.И. Мигачев, Л.Л. Попов, С.В. Тихомиров; под ред. Л.Л. Попова. 3-е изд., перераб. и доп. М.: Издательство Юрайт, 2013.

3. Бахрах Д.Н. Административное право России: учебник для вузов. М., 2000.

4. Беккариа Ч. О преступлениях и наказаниях. М.,2011.

5. Евтихиев И.И. Виды и формы административной деятельности органов государственного управления. Дис. ... д-ра юрид. наук. М., 1948.

6. Ноздрачев А.Ф. Административные решения и акты в России и во Франции // Административные процедуры и контроль в свете европейского опыта / Под ред. Т.Я. Хабриевой и Ж. Марку. М.: Статут, 2011.

7. Тихомиров Ю.А. Административные процедуры: доктрина и практика // Административные процедуры и контроль в свете европейского опыта / Под ред. Т.Я. Хабриевой и Ж. Марку. М.: Статут, 2011.

8. Юсупов В.А. Правоприменительная деятельность органов управления. М.: Юридическая литература, 1979.

9. Соломатина Е.А. Правовое регулирование деятельности полиции в зарубежных странах // NB: Российское полицейское право. - 2013. - 3. - C. 104 - 118. DOI: 10.7256/23064218.2013.3.8916. URL: http://www.e-notabene.ru/pm/article_8916.html

10. Трегубова Е.В. Административные запреты в сфере осуществления полицейской деятельности // NB: Российское полицейское право. - 2013. - 1. - C. 25 - 44. DOI: 10.7256/23064218.2013.1.718. URL: http://www.e-notabene.ru/pm/article_718.html

11. Куракин А.В., Костенников М.В. Принципы организации и деятельности российской полиции // NB: Российское полицейское право. - 2013. - 2. - C. 22 - 49. DOI: 10.7256/23064218.2013.2.799. URL: http://www.e-notabene.ru/pm/article_799.html

12. Трегубова Е.В. Административные запреты в сфере осуществления полицейской деятельности. // Полицейская деятельность. - 2011. - 2. - С. 42 - 48. 


\section{References (transliteration):}

1. Bakhrakh D.N. Administrativnoe pravo Rossii: uchebnik dlya vuzov. M., 2000.

2. Bekkaria Ch. O prestupleniyakh i nakazaniyakh. M.,2011.

3. Evtikhiev I.I. Vidy i formy administrativnoi deyatel'nosti organov gosudarstvennogo upravleniya. Dis. ... d-ra yurid. nauk. M., 1948.

4. Nozdrachev A.F. Administrativnye resheniya $\mathrm{i}$ akty $v$ Rossii $\mathrm{i}$ vo Frantsii // Administrativnye protsedury i kontrol' $v$ svete evropeiskogo opyta / Pod red. T.Ya. Khabrievoi i Zh. Marku. M.: Statut, 2011.

5. Tikhomirov Yu.A. Administrativnye protsedury: doktrina i praktika // Administrativnye protsedury i kontrol' v svete evropeiskogo opyta / Pod red. T.Ya. Khabrievoi i Zh. Marku. M.: Statut, 2011.

6. Yusupov V.A. Pravoprimenitel'naya deyatel'nost' organov upravleniya. M.: Yuridicheskaya literatura, 1979.

7. Solomatina E.A. Pravovoe regulirovanie deyatel'nosti politsii v zarubezhnykh stranakh // NB: Rossiiskoe politseiskoe pravo. -2013. -3. - C. 104 -118. DOI: 10.7256/2306-4218.2013.3.8916. URL: http://www.e-notabene.ru/pm/article_8916.html

8. Tregubova E.V. Administrativnye zaprety $v$ sfere osushchestvleniya politseiskoi deyatel'nosti // NB: Rossiiskoe politseiskoe pravo. -2013. -1. -C. 25 - 44. DOI: 10.7256/2306-4218.2013.1.718. URL: http://www.e-notabene.ru/pm/article_718.html

9. Kurakin A.V., Kostennikov M.V. Printsipy organizatsii i deyatel'nosti rossiiskoi politsii // NB: Rossiiskoe politseiskoe pravo. - 2013. - 2. - C. 22 - 49. DOI: 10.7256/2306-4218.2013.2.799. URL: http://www.e-notabene.ru/pm/article_799.html

10. Tregubova E.V. Administrativnye zaprety $\mathrm{v}$ sfere osushchestvleniya politseiskoi deyatel'nosti. // Politseiskaya deyatel'nost'. - 2011. - 2. - C. $42-48$. 